\title{
Research Article \\ Immigrants' Human Capital Return and the Relationship between Risk and Return: The Case of Canada
}

\author{
Sana Mami Kefi \\ Mediterranean School of Business (MSB), Tunis, Tunisia \\ sana.mami@msb.tn
}

Received date: 17 August 2016; Accepted date: 2 January 2017; Published date: 1 March 2017

Academic Editor: Chokri Aloui

Copyright (C) 2017. Sana Mami Kefi . Distributed under Creative Commons CC-BY 4.0

\begin{abstract}
We consider that an immigrant has a portfolio of human capital consisting of education, work experience and languages and each asset is characterized by a risk and a return. The approach of Mincer (1974) was adopted and the effect of the similarity between Canada and the country of origin on salary was taken into account to determine the returns of these various components of human capital. Then, the methodology of Pereira and Martins (2002) was used to assess the risks associated with human capital, i.e. the risk for an individual to be in the lower part of the income distribution. The results indicate that human capital is not perfectly transferable and show that the relationship between risk and return is similar to that relating to financial assets: it is negative for assets that represent insurance for their owners and positive for the others. In addition, the accumulation of work experience in Canada and similar countries is accompanied by an increase in risk and a decrease in returns. Contrary to our expectations, the results indicate that the risk does not decrease with education level.
\end{abstract}

Keywords: Risk, return on human capital, quantile regression

\section{Introduction}

Canada is a country where immigration occupies a very important place. According to Statistics Canada, in 2011, $20.6 \%$ of the total population was born abroad; this assigns to Canada the second place after Australia (26.8\% in 2010). Moreover, the proportion of foreign-born population would reach between 25\% and $28 \%$ by 2031 (Statistics Canada 2010). When new immigrants arrive in the country, they bring with them their human capital which consists of, among others, education and labor market experience. However, the differences from one country to another, in terms of education systems and the requirements

Cite this Article as: Sana Mami Kefi (2017), "Immigrants' Human Capital Return and the Relationship between Risk and Return: The Case of Canada" Journal of Economics Studies and Research, Vol. 2017 (2017), Article ID 870267, DOI: 10.5171/2017. 870267 
of labor market may complicate the transfer of this human capital acquired in the country of origin and affect its return. It is often difficult for an immigrant to take up an employment that matched his qualifications. He is then faced with the problem of over-qualification and the risk of being in the lower part of the income distribution.

The contribution of this paper falls within the framework of the literature on human capital of immigrants. Our motivation to explore this field of research stems from the affluence and diversity of this investment. To our knowledge, no study has focused on the relationship between the risk and return on the human capital of an immigrant. An analogy is made with the financial sector considering that the immigrant has a human capital portfolio consisting of education (the place of obtaining the highest degree varies), labor market experience (In Canada or abroad), and languages. This study will contribute to a better understanding of the situation of immigrants in Canada and to see how their human capital is perceived by the employers on the Canadian labor market. It will also help identify the assets (degrees and experiences) that demonstrate the best combinations of risk and return for the immigrant.

The questions we try to answer through this paper refer to education and labor market experience. We believe that, for the immigrant, the place of obtaining the highest degree and the place of acquisition of the professional experience are at the origin of the differences in returns and risks associated with these assets. In fact, we are going to empirically check the following assumptions. Firstly, there would be a disadvantage in terms of salary for the immigrants who obtained their highest degree abroad. Similarly, the labor market experience gained in Canada will have the highest return. Secondly, the gap would be greater if the difference between Canada and the country of origin of the immigrant is huge (in terms of education systems for example). Thirdly, the labor market experience in a country non-similar to Canada would be most risky (compared to experiences gained in Canada or a similar country). Fourthly, as and when an individual advances in his studies, the return (risk) on education is expected to increase (decrease). Generally, by considering the various degrees and labor market experiences together, we expect that an increase in risk is to be compensated by a higher return. In addition to the verification of these assumptions, we are concerned with the evolution in time of the risks and returns on the different types of labor market experience. We expect that the risk of work experience abroad (in Canada) increases (decreases) over time.

The results confirm the first three hypotheses. However, contrarily to our expectations, it seems that a higher educational level is not necessarily accompanied with a lower risk (except for a graduate diploma which has a lower risk as compared to Bachelor. As in the case of financial assets, our results suggest a ' $V$ ' shaped relationship between risk and return on human capital. As regards the evolution of risk and return on work experience, according to our estimates, the risk of work experience in a country not similar to Canada increases through time. We see the same trend for the return (even if the latter is negative). As to the work experiences in Canada and similar countries, it seems that their risks increase and their returns decrease over the years.

In this study, we first consider a variant of the Mincer's (1974) approach to determine the returns of different components of the human capital of an immigrant. Through the place where the highest diploma and work experience were obtained, we consider the effect of the similarity between Canada and the 
country of origin of the immigrant on wages. Then, assuming that the immigrant holds a portfolio which consists of different assets (educational level, work experience, languages...), we analyze the relationship between risk and return on human capital and compare it to the case of financial assets.

This paper is organized as follows. Section 2 compares some aspects of the human capital with those of the physical capital. Section 3 discusses the growth rate of the labor income per capita as a proxy for the return on human capital and the shortcomings of this measure. Section 4 provides a discussion of the transferability of the immigrant's human capital. Section 5 presents the data and methodology. Section 6 describes the model. Section 7 analyzes the results of the estimation. Section 8 discusses the relationship between risk and return on the human capital of immigrants. The last section concludes with the main results.

\section{Human Capital Vs. Physical Capital}

According to Jagannathan and Wang (1996), the human capital is similar to the physical capital as it is exchangeable. Life insurance and unemployment insurance are examples of contracts based on the risk of human capital. Unlike Jagannathan and Wang (1996), Palacios-Huerta (2003a) considers that human capital is both risky and non-exchangeable. He points out the fact that the returns on the human capital vary among individuals while the return on a financial asset is the same for all. Furthermore, according to this author, for college studies, the investment in human capital is more profitable than investing in exchangeable assets. In addition to the nonexchangeable nature of the human capital, Palacios-Huerta (2003a) considers that the taxation of this capital is not the same as that applied to financial assets and that those differences explain the fact that the two assets do not have the same return per unit of risk.

Levhari and Weiss (1974) assume that the human capital is difficult to diversify. According to these authors, from the perspective of the individual, the human capital is more risky than the physical capital as it can neither be sold or bought, nor separated from its owner. Furthermore, according to Hanchane et al. (2006), unlike physical capital, the human capital cannot be transferred following the individual's death.

\section{Measuring the Return on Human Capital}

Many studies which considered the human capital as an important component of the market portfolio (for example Jahannathan and Wang (1993), Jagannathan et al. (1998)), used the growth rate of the labor income per capita to measure the return on human capital. According to Palacios-Huerta (2003b), this measure has some limits including the fact that it does not take into consideration the work experience of the individual which is, nevertheless, an important component of his human capital.

Unlike Jagannathan and Wang (1996), Campbell and Korniotis's (2008) measure of the return on human capital is not based on aggregate data on the labor income. They argue that as the financial assets are not equally distributed among individuals, the use of aggregate data is irrelevant. Moreover, according to Campbell and Korniotis (2008), the aggregate labor income and the labor income of the richest households are not fully correlated. Thus, based on the assumption that the high-income households are more likely to invest in the stock market, Campbell and Korniotis (2008) measure the growth rate of labor income of the households making part of the richest $10 \%, 5 \%$ and $1 \%$. These 
measurements represent a proxy of the return on human capital.

Besides Palacios-Huerta's critique (2003b), we believe that the growth rate of labor income per capita is not a good approximation of the return on human capital, as the investment in the latter is a long term investment and therefore, it is inappropriate to measure its performance on a monthly basis. Indeed, a few years of education are required before a person can obtain a degree and note the contribution of the investment.

In addition, the growth rate of labor income per capita is a measure which might be underestimated if we consider an immigration country like Canada. Indeed, as has been shown by some studies (Friedberg (2000), Finnie and Meng (2002)), the human capital (education and work experience) of immigrants acquired abroad is undervalued in the host country. It would seem more appropriate to separately estimate the returns on the human capital acquired abroad and that acquired in the host country.

\section{Human Capital of Immigrants}

The return on human capital of an individual is closely linked to his country of origin (Friedberg (2000)). Two factors explain the differences in return through the various origin groups: the variation in the quality of education across countries and the degree of compatibility of the human capital acquired abroad with labor market requirements in the host country. Thus, according to Friedberg (2000), the education and work experience acquired abroad would be even more valued than the levels of economic development and the institutional frameworks in home and host countries are similar.

Friedberg (2000) finds that the return on a year of education or work experience in the host country (Israel) is higher for a person from Israel. She attributes this to the fact that the latter has an advantage over an immigrant in terms of knowledge of the language and specificities of the host country. Moreover, the return on work experience acquired abroad by the immigrant is almost nil and the age at immigration influences the returns on human capital acquired abroad (Schaafsma and Sweetman (2001)). Indeed, their study demonstrates that the returns on human capital acquired abroad (education and work experience) are lower for individuals who immigrate at a relatively advanced age. They also find that the wage gap between immigrants belonging to visible minorities and Canadian natives increases with age at immigration.

In their study on the evolution of immigrant wages in Quebec, compared to that of Ontario and British Columbia, Boudarbat and Boulet (2007) highlight the difficulty that immigrants have to transfer and assert their human capital acquired abroad. They also find that work experience in Canada has much more value than experience abroad.

According to Boudarbat and Boulet (2007), the recognition of the experience acquired abroad is a major problem facing the authorities. Thus, they emphasize the need to establish mechanisms to promote the transfer of foreign experience and facilitate the access of newly graduated foreign students to the labor market. The latters generally have little foreign experience. Their admission in Canada as immigrants would allow them to earlier access to the labor market and therefore to accumulate more Canadian experience. In addition, Boudarbat and Boulet (2007) point out the advantage that this category of prospective immigrants has in terms of knowledge of the country.

Moreover, according to Aydemir and Skuterud (2005), lower returns on the 
work experience abroad can explain one third of the deterioration of wages on the time of entry of immigrants. However, they find no apparent connection between the decline in returns to education abroad and this deterioration. Kogan (2004) finds that the work experience acquired abroad increases the risk of dismissal for the immigrant. $\mathrm{He}$ also shows that this risk is higher for immigrants whose level of education is low.

\section{Data and Methodology}

The data for the analysis come from the 2001Census of Canada public use microdata files. The dataset is related to male immigrants aged between 18 and 65 years at the time of the census. They speak at least one of the two official languages, are not studying and reported that they had worked mostly full-time during the reference year (preceding the census year). Only immigrants who were in the country for at least 2 years were included in the sample which comprises 29213 observations. Indeed, we believe that within 2 years, immigrants would have had time to settle in Canada.

For each individual, the weekly wage is calculated by dividing the annual salary by the number of weeks worked during the year preceding the census. Moreover, as the year of immigration is sometimes presented in intervals of 2 years, we consider the middle year. In case the interval is of one year, we choose the lower bound. The variable 'age at immigration' is given as an interval of 4 years and over. We therefore had to estimate it by using the following formula: $\max (0$, year of immigration (census year - age)).

As regards education, unlike many studies which consider the total number of years of education (for example Schaafsma and Sweetman (2001), Aydemir and Skuterud (2005)), as in Boudarbat and Boulet
(2007), we use the variable 'highest earned degree' and consider four levels relative to no diploma): secondary, college, bachelor and graduate. Even though the number of years of education (in Canada and abroad) does not appear directly in the estimated model, it was necessary, however, to be determined in order to calculate work experience (in Canada and abroad). Indeed, the work experience of an individual is not a variable reported in the census. We were inspired by the approach of Schaafsma and Sweetman (2001) to separate education and work experience into domestic and foreign components. Thus, by assuming that a person starts his studies at the age of 6 years on a continuous basis and embark on work after finishing his studies, we first determine the number of years of education in Canada EDC $=\max (0$, total number of years of education +6 - age at immigration). Education abroad is then EDA = max $(0$, total number of years of study - EDC). Then, we determine the potential experience abroad EXPA = max (0, age at immigration - EDA - 6). Potential experience in Canada is then EXPC $=$ max $(0$, total number of years of experience - EXPA), where the total number of years of experience is max $(0$, age - total number of years of education 6).

The number of years of study in Canada is used to determine whether the highest degree was obtained in Canada or abroad (based on the number of years of study required to obtain a diploma). In case the degree was obtained abroad, we have made a distinction between two groups of countries based on the country of birth of the immigrant: countries where education systems are similar to Canadian systems versus dissimilar ones. It shall be noted that in the public use micro data files of Statistics Canada, the information concerning the country of origin of an immigrant is not precise as the country of birth is often grouped with 
other countries. The classification that seems to be the most plausible is to include in the group of the most similar countries the following countries: The United States, Great Britain, Germany, Italy, Netherlands, Poland, Portugal, France, Greece and the group of countries that includes Austria, Belgium, Czech Republic, Slovakia, Hungary, Romania,
Denmark, Finland, Iceland, Norway, Sweden, Liechtenstein, Luxembourg, Monaco, Switzerland, Bulgaria, Ireland, Albania, Andorre, Gibraltar, Malta, San Marino, Spain and the Holy See. Table 1.1 below shows the averages of some variables such as salary (in logarithm), work experience, age and age at immigration.

Table 1: Averages of the variables

\begin{tabular}{|l|c|c|}
\hline \multicolumn{1}{|c|}{ Variables } & \multicolumn{2}{c|}{ Immigrants } \\
\hline & $\mathbf{2 0 0 1}$ & $\mathbf{1 9 9 6}$ \\
\hline Log of wage & 6.6 & 6.4 \\
\hline Years since immigration & 21.5 & 16.3 \\
\hline Years of experience in a similar country & 1.7 & 3.3 \\
\hline Years of experience in a non-similar country & 4.5 & 4.6 \\
\hline Years of experience in Canada & 18 & 14 \\
\hline Age at immigration & 22.7 & 25.4 \\
\hline Age & 44.2 & 41.8 \\
\hline
\end{tabular}

\section{The Model}

The estimated model is a variant of the Mincer approach (1974). We consider the wage as a function of the highest earned degree, work experience and knowledge of official languages. For education, we take account of the place where the highest degree was obtained. Indeed, given the importance of the latter during job search, it is possible that from the point of view of an employer, a diploma in Canada would not have the same value as a degree obtained somewhere else (in a country similar or not similar to Canada). In addition, as has been suggested in several studies (for example Friedberg (200) Boudabrat and Boulet 2007)), a distinction is made between work experience in Canada and the experience acquired abroad. Moreover, the experience abroad is classified either as an experience in a country similar to
Canada, or as an experience in a nonsimilar country. In order to clarify the issue of transferability of human capital, we also include cross terms that take into account the interaction between work experience in Canada and the one abroad and between levels of education and the place of obtaining the highest degree. The model is as follows:

lwage $\mathrm{i}_{\mathrm{i}}=\mathrm{c}_{1}+\mathrm{c}_{2} \mathrm{SEC}_{\mathrm{i}}+\mathrm{c}_{3} \mathrm{COL}_{\mathrm{i}}+\mathrm{c}_{4} \mathrm{BAC}_{\mathrm{i}}+\mathrm{c}_{5} \mathrm{GRAD}$ ${ }_{i}+\mathrm{c}_{6}$ EXPSIM $_{\mathrm{i}}+\mathrm{c}_{7}$ EXPSIM $_{\mathrm{i}}{ }^{2}+\mathrm{c}_{8}$ EXPNONSIM $_{\mathrm{i}}+$ $+c_{9}$ EXPNONSIM $_{\mathrm{i}}^{2}+\mathrm{c}_{10}$ EXPC $_{\mathrm{i}}+\mathrm{c}_{11}$ EXPC $_{\mathrm{i}}^{2}+\mathrm{c}_{12}$

SIM $_{\mathrm{i}}+\mathrm{c}_{13}$ NONSIM $_{\mathrm{i}}+\mathrm{c}_{14}$ EXPC $_{\mathrm{i}}{ }^{*}$ EXPSIM $_{\mathrm{i}}+$ $\mathrm{c}_{15}$ EXPC $_{\mathrm{i}}{ }^{*}$ EXPNONSIM $_{\mathrm{i}}+\mathrm{c}_{16} \mathrm{GRAD}_{\mathrm{i}}{ }^{*}$ SIM $_{\mathrm{i}}+\mathrm{c}_{17}$ GRAD $_{\mathrm{i}}^{*}$ NONSIM $_{\mathrm{i}}+\mathrm{C}_{18}$ BAC $_{\mathrm{i}}{ }^{*} \operatorname{SIM}_{\mathrm{i}}+\varepsilon_{\mathrm{i}}$

where $\mathrm{i}=1,2 \ldots ., \mathrm{n}, \mathrm{n}$ is the number of individuals in the sample and variables are described in Table 1.2. 
Table 2: Definition of the variables

\begin{tabular}{|l|l|}
\hline Variable & Description \\
\hline lwage & log of weekly wage \\
\hline SEC & $\begin{array}{l}\text { a dummy variable that takes the value } 1 \text { when the highest degree is a } \\
\text { secondary diploma }\end{array}$ \\
\hline COL & $\begin{array}{l}\text { a dummy variable that takes the value } 1 \text { when the highest degree is a college } \\
\text { diploma }\end{array}$ \\
\hline BAC & $\begin{array}{l}\text { a dummy variable that takes the value } 1 \text { when the highest degree is the } \\
\text { Bachelor }\end{array}$ \\
\hline GRAD & $\begin{array}{l}\text { a dummy variable that takes the value } 1 \text { when the highest degree is a } \\
\text { graduate diploma }\end{array}$ \\
\hline EXPSIM & $\begin{array}{l}\text { the number of years of work experience abroad in a country similar to } \\
\text { Canada }\end{array}$ \\
\hline EXPNONSIM & $\begin{array}{l}\text { the number of years of work experience abroad in a non-similar country } \\
\text { the number of years of work experience in Canada }\end{array}$ \\
\hline EXPC & $\begin{array}{l}\text { a dummy variable that takes the value } 1 \text { when the highest degree was earned } \\
\text { in a country similar to Canada }\end{array}$ \\
\hline SIM & $\begin{array}{l}\text { a dummy variable that takes the value } 1 \text { if the highest degree was obtained } \\
\text { in a non-similar country }\end{array}$ \\
\hline NONSIM & a dummy variable that takes the value 1 when the individual is bilingual \\
\hline BIL &
\end{tabular}

\section{Results}

Table 1.3 reports the results of the estimation of model (1.1) by the Ordinary Least Squares (OLS) method using a sample weighting. The average return of a graduate degree in comparison to the bachelor is $12.17 \%$. The bachelor's degree provides a higher return of $32.6 \%$ in comparison with a college certificate.

Table 3: Return on human capital of immigrants

\begin{tabular}{|l|c|c|}
\hline \multicolumn{3}{|c|}{ Dependent variable: lwage } \\
\hline Explanatory variables & Coef. & Std. error \\
\hline & & \\
\hline Constant & $5.856^{* * *}$ & 0.025 \\
\hline SEC & $0.145^{* * *}$ & 0.021 \\
\hline COL & $0.303^{* * *}$ & 0.019 \\
\hline BAC & $0.629^{* * *}$ & 0.026 \\
\hline GRAD & $0.751^{* * *}$ & 0.032 \\
\hline
\end{tabular}




\begin{tabular}{|c|c|c|}
\hline EXPSIM & $0.031^{* * *}$ & 0.005 \\
\hline EXPSIM $^{2}$ & $-0.001^{* * *}$ & 0.000 \\
\hline EXPNONSIM & 0.004 & 0.003 \\
\hline EXP NONSIM ${ }^{2}$ & $-0.000^{*}$ & 0.000 \\
\hline EXPC & $0.039^{* * *}$ & 0.002 \\
\hline EXPC $^{2}$ & $-0.001^{* * *}$ & 0.000 \\
\hline SIM & 0.008 & 0.025 \\
\hline NONSIM & $-0.044^{* *}$ & 0.021 \\
\hline EXPC* EXPSIM & $-0.001^{* * *}$ & 0.000 \\
\hline EXPC* EXPNONSIM & $-0.001^{* * *}$ & 0.000 \\
\hline GRAD * SIM & $-0.078^{*}$ & 0.048 \\
\hline GRAD * NONSIM & $-0.079^{* *}$ & 0.040 \\
\hline BAC* SIM & -0.034 & 0.049 \\
\hline BAC* NONSIM & $-0.126^{* * *}$ & 0.033 \\
\hline BIL & $-0.098^{* * *}$ & 0.016 \\
\hline & \multicolumn{2}{|c|}{ Weighted statistics } \\
\hline $\mathbf{R}^{2}$ & \multicolumn{2}{|c|}{0.098} \\
\hline Adjusted R ${ }^{2}$ & \multicolumn{2}{|c|}{0.097} \\
\hline
\end{tabular}

\section{Note: ${ }^{* * *} p<0.01,{ }^{* *} p<0.05,{ }^{*} p<0.1$. See Table 1.2 for the definition of the variables}

Obtaining the highest degree in a country non-similar to Canada could constitute a disadvantage for the individual in terms of salary if compared to the case in which he would have obtained it in Canada. In addition, although the SIM variable is not statistically significant, the hypothesis of equality between its coefficient and that of NONSIM is rejected at 5\% significance level. Furthermore, the interaction between GRAD and NONSIM is negative and significantly different from zero at $5 \%$ significance level. This indicates that the immigrant, who completed his university studies in a country nonsimilar to Canada, has a return on education that is lower than that of an immigrant who obtained the same degree in Canada. This is also true for the Bachelor's degree. However, the fact of having obtained such degrees in a country similar to Canada does not seem to affect their returns. Concerning work experience, the results indicate that the average return of the first year of experience in a country similar to Canada is $3.07 \%$. In the case of a country nonsimilar to Canada, the return is almost zero (insignificant coefficient). Work experience in Canada provides an average return of $3.81 \%$ in the first year, which is a better return than in the previous cases. It should also be noted that even though the coefficient of the variable EXPNONSIM is not statistically significant, the null hypothesis of equality of the returns of EXPSIM and EXPNONSIM is rejected at $1 \%$ significance level. The interaction between work experience in Canada and abroad is negative and significantly different from zero at $1 \%$ significance level. This confirms the idea that immigrants have difficulties in transferring and asserting their human 
capital acquired abroad. Contrary to our expectations, bilingualism provides a lower return than monolingualism which is of about $-9.77 \%$. One possible explanation for this result is that the province of residence of the immigrant is not considered in the analysis. However, as there is a high concentration of bilingual immigrants in Quebec, the variable bilingualism would be an indicator of Quebec as a place of residence. Yet, we know that the price level and the nominal wage particularly is $10 \%$ lower in Quebec than in other provinces.

\section{Human capital and risk}

According to Levhari and Weiss (1974), the expected return on human capital is higher than a risk-free asset only if the level of education positively affects the variance of incomes. They show that under the assumptions of a decreasing absolute risk aversion and an increasing risk, and when the individual is a net borrower during the investment period, any increase in the interest rates would have a negative impact on investment in human capital. In case he is a net lender, the effect is uncertain. Under the same assumptions, Levhari and Weiss (1974) find that an increase in initial wealth would encourage investing in human capital. Their results indicate that uncertainty can either stimulate or slow down the investment in human capital.

According to Christiansen et al. (2007), there are major differences between the fields and levels of education in terms of return and return per unit of risk. By considering different levels and fields of study at the same time, they are able to determine a set of efficient degrees according to the mean-variance criterion used in financial analysis. By assimilating the combination of level and field of study to an asset, they estimated the gain in terms of return per unit of risk from adding an asset to another already existing one.

Using data relative to 16 countries, Pereira and Martins (2002) find that the relationship between risk and return of education is positive except for Switzerland, Germany, the United States and Sweden. The first two displayed a high return and low risk whereas the others are characterized by a low return and a relatively high risk. Their results indicate that the investment in education is similar to an investment in a financial asset.

In the United States as well as in other developed countries, labor income represents at least $2 / 3$ of the total income (Palacios-Huerta (2003a). Based on U.S. data, Palacios-Huerta (2003a) shows that earnings per unit of risk from investing in college studies (or a higher level) exceed those relating to investment in risky financial assets and the difference ranges from $5 \%$ to more than $20 \%$.

Moreover, according to Hartog et al. (2007), the expected return and the risk are the criteria on which an individual relies to take his decision about continuing his studies. They distinguish between two types of risk: the first is the risk 'ex ante' due to uncertainty about the academic performance of the individual, the uncertainty about his position in the income distribution upon entering the labor market and to the market risk (technological progress etc..). The second type is the 'ex post' risk; it originates mainly from the selection process in the labor market.

Hartog et al. (2007) find that the investment in college studies is similar to investing in a portfolio of 30 randomly selected stocks. The measure of the risk of investment in human capital that they adopt is the internal rate of return on education, which they identify as the discount rate such as the discounted 
values of future incomes corresponding to two levels of education are equal.

Hartog and Vijverberg (2007) analyze the risk associated with the choice of the program of study. Their results indicate the presence of a positive relationship between risk and expected gain. They assimilated a study program to a portfolio of assets weighted according to the time devoted to study some courses or to develop certain skills (mathematics, language ....). They considered the choice, for an individual, between specializing in a specific domain and having a general education. They demonstrate that for individuals (men and women) with a college education, the risk associated with a specialization in mathematics or languages is less than that relating to the combination of these two skills.

Hanchane et al. (2006) analyze the choice of education in a context of uncertainty. They argue that when making decisions about education, individuals cannot perfectly predict their future situations, particularly because of the existence of over-qualification and unemployment. According to these authors, education is an irreversible investment. They consider that in each period, the individual who is pursuing studies has the option to stop studying and to work at a wage that randomly depends on his level of education. He cannot return to school after exercising the option. According to Hanchane et al. (2006), this risk (variance of incomes) has the effect of encouraging the individual to pursue his studies because he could not go back on his decision.

They find that the more the individual is rich, the more he invests in education. Their results indicate that, other things being equal, the level of education and the wage of a wealthy individual are higher than those of a less rich one because the opportunity cost of the human capital is lower for the first. They note that possible unemployment encourages people to pursue their studies because it leads to a decrease in this opportunity cost.

The results of the model developed by Hanchane et al. (2006) indicate that the individual invests more in human capital when the risk associated with wage increases. In fact, according to Hanchane et al. (2006), under the hypothesis that education is a risky asset, the individual faces the risk that the investment will not be remunerated. Unless there is a sufficiently high risk premium, he will have to reduce his investment. According to Hanchane et al. (2006), the investment in human capital is affected by different types of uncertainties: an uncertainty about the process of accumulation of human capital (academic performance of students etc.) and an uncertainty regarding the future market situation. The first negatively affects the investment in human capital, while the second can stimulate it. These opposing effects explain why it is difficult to clearly determine 'ex ante ', the impact of uncertainty on investment in human capital.

\section{Risk and Return on Human Capital}

In this study, we consider that each individual has a portfolio of different assets (education, labor market experience, knowledge of languages ...). Thus, each variable of interest in the estimated models is an asset that could be characterized, just like a financial asset, by a return and a risk.

Christiansen et al. (2008) find that, among 11 groups of education, the economists are most likely to invest in the stock market. However, each individual is investing in human capital. Although the costs of education constitute a barrier to the pursuit of studies, the option of accumulating labor market experience still represents an investment in human capital. 
To measure the risks associated with different levels of study, with labor market experience (acquired in Canada as well as abroad) and the knowledge of languages, we adopt the methodology of Pereira and Martins (2002). It consists in estimating the model for the first and last deciles. The risk relative to an asset is the difference between the coefficient of this asset (its return) in the regression of the last decile and its coefficient in the regression of the first decile. Based upon data on 16 countries, Pereira and Martins (2002) consider this measure to study the relationship between the risk and return of investment in education. According to Pereira and Martins (2002), its use is based on the assumption that prior to entering the labor market, the individual does not know what would be his position in the income distribution. They consider that when the return to education is much higher in the last decile (the difference between the coefficient of education in the last decile and that of the first decile is small), it means that the risk that the individual faces is high (the risk is almost nil). According to Andini (2009, p.307), Pereira and Martins (2002) use a measure of risk that is widely accepted in the literature on the effect of education on income dispersion. In addition, Machado and Mata (2001) first include the number of years of study in the regression. Then, they distinguish between different types of studies. The distribution of wages which they consider is determined from a sample of individuals with different levels of education. Their results indicate that education increases wage inequality. Concerning the measurement of risk of Pereira and Martins (2002), a high return of an asset in the last decile of the wage distribution, compared to the first decile, indicates that the remuneration of this asset is better for the richest people. Conversely, if the effect of this asset (on income) is relatively high for individuals who are at the bottom of the wage distribution, this suggests that this asset is more valued in the case of low-wage jobs and thus plays the role of insurance guaranteeing a minimum income for its holder. It should be noted that, as in Machado and Mata (2001), we consider, in this study, the distribution of wages of individuals from different levels of education. Another approach would be to distinguish between degrees and to use the probability that an individual is in the first decile of the wage distribution relative to persons holding the same degree as him.

The estimation of model (1.2) by OLS gives the average returns of the different variables. To determine risk, the model (1.2) is estimated by the quantile regression method. The results for the $1^{\text {st }}$ and $9^{\text {th }}$ deciles are reported in Table 1.4.

$$
\begin{aligned}
& \text { lwage }_{\mathrm{i}}=\mathrm{c}_{1}+\mathrm{c}_{2} \mathrm{SEC}_{\mathrm{i}}+\mathrm{c}_{3} \mathrm{COL}_{\mathrm{i}}+\mathrm{c}_{4} \mathrm{BAC}_{\mathrm{i}}+\mathrm{c}_{5} \mathrm{GRAD} \\
& +\mathrm{c}_{6} \mathrm{EXPSIM}_{\mathrm{i}}+\mathrm{c}_{7} \text { EXPSIM }_{\mathrm{i}}{ }^{2}+\mathrm{c}_{8} \text { EXPNONSIM }_{\mathrm{i}}+ \\
& +\mathrm{c}_{9} \text { EXPNONSIM }_{\mathrm{i}}{ }^{2}+\mathrm{c}_{10} \mathrm{EXPC}_{\mathrm{i}} \\
& +\mathrm{c}_{11} \mathrm{EXPC}_{\mathrm{i}}{ }^{2}+\mathrm{c}_{12} \mathrm{SIM}_{\mathrm{i}}+\mathrm{c}_{13} \text { NONSIM }_{\mathrm{i}}+\mathrm{c}_{14} \mathrm{BIL}_{\mathrm{i}} \\
& +\varepsilon_{\mathrm{i}} \quad(1.2)
\end{aligned}
$$

Table 4: Quantile Regression Results

\begin{tabular}{|l|r|r|r|r|}
\hline & \multicolumn{2}{|c|}{$1^{\text {st }}$ decile } & \multicolumn{2}{c|}{ 9 $^{\text {th }}$ decile } \\
\hline & Coef. & Std. error & Coef. & Std. error \\
\hline SEC & $0.218^{* * *}$ & 0.035 & $0.144^{* * *}$ & 0.016 \\
\hline COL & $0.429^{* * *}$ & 0.041 & $0.279^{* * *}$ & 0.016 \\
\hline BAC & $0.621^{* * *}$ & 0.054 & $0.571^{* * *}$ & 0.029 \\
\hline GRAD & $0.708^{* * *}$ & 0.037 & $0.715^{* * *}$ & 0.024 \\
\hline
\end{tabular}




\begin{tabular}{|c|c|c|c|c|}
\hline EXPSIM & $0.025^{* * *}$ & 0.009 & $0.012^{* * *}$ & 0.004 \\
\hline EXPSIM $^{2}$ & $-0.001^{* *}$ & 0.000 & -0.000 & 0.000 \\
\hline EXPNONSIM & -0.008 & 0.006 & -0.001 & 0.003 \\
\hline EXPNONSIM $^{2}$ & -0.000 & 0.000 & 0.000 & 0.000 \\
\hline EXPC & $0.046^{* * *}$ & 0.004 & $0.029 * * *$ & 0.003 \\
\hline EXPC $^{2}$ & $-0.001^{* * *}$ & 0.000 & $-0.000 * * *$ & 0.000 \\
\hline SIM & -0.062 & 0.053 & 0.036 & 0.026 \\
\hline NONSIM & $-0.152^{* * *}$ & 0.039 & $-0.081^{* * *}$ & 0.015 \\
\hline BIL & $-0.138^{* * *}$ & 0.036 & $-0.038^{* *}$ & 0.019 \\
\hline Constant & $5.112^{* * *}$ & 0.045 & $6.679 * * *$ & 0.025 \\
\hline $\mathbf{N}$ & & 29213 & & \\
\hline Pseudo $\mathrm{R}^{2}$ & 0.040 & & 0.087 & \\
\hline
\end{tabular}

\section{Note: ${ }^{* * *} \mathbf{p}<0.01,{ }^{* *} \mathbf{p}<0.05,{ }^{*} \mathbf{p}<0.1$. See Table 1.2 for the definition of the variables}

The tests of significance of risks indicate that only the risks associated with bachelor, graduate studies and labor market experience abroad are statistically insignificant. This suggests that there are levels of study with a non-zero risk and others that do not pose a risk.

Fig 1.1 represents all the assets corresponding to the sample of immigrants in a risk-return space. It seems that the labor market experience in Canada is the best choice among the options considered and that work experience in a country non-similar to Canada is the most risky but also the less profitable (its return is even negative). This confirms the general result in the literature that immigrants have difficulties in transferring and asserting their human capital acquired abroad (Friedberg (2000), Boudarbat and Boulet (2007)).

Moreover, among all levels of education, the Bachelor's degree is the most risky asset, but also the one with the higher return. Note that for secondary and collegial degrees, as well as labor market experience in Canada and similar countries, the gap between the return on the lowest decile and that corresponding to the first decile is negative. This means that, all things being equal, they are assets that have good returns in the case of bad circumstances. By assimilating the human capital of an individual to a portfolio, investing in at least one of these assets would reduce the risk of this portfolio and would therefore constitute an insurance against any economic downturn. Recall that in finance, an asset whose beta is negative is an asset whose return evolves in the opposite direction of the market portfolio and is less than the risk-free rate. As in Campbell (1996), we consider that the market portfolio is composed not only of financial assets but also of human capital. Concerning labor market experiences in Canada and similar countries, it seems that they provide lower returns than the risk free rate (at least until the eighth year for EXPSIM). Since we have, in the sample, considered individuals who have declared having worked full-time during the reference year (2000), the low level of returns means that the immigrant has accepted a position despite the fact that the assessment of his professional experience was not in his favor. In other words and to make the analogy with the financial sector, it is as if the immigrant perceives his experience as an insurance to 
guarantee him a return in case he is faced with an economic downturn. The more he accumulates years of experience, the more the relationship between him and his employer would be strengthened, the less probable for him to be dismissed in case of recession for example (McDonald and Worswick (1997), Kogan (2004)). Furthermore, this could also reflect the difficulty of integrating immigrants into the Canadian labor market and the fact that they held positions for which they would be overqualified because of an underestimation of their skills by the employers.

We observe that the relationship between risk and return is initially negative for the assets that represent insurance for their holders (COL, and EXPC-1 and EXPSIM-1). Then it becomes positive for the others (EXPNONSIM-1, GRAD and BAC). This result is similar to what Cloninger and et al. (2004) have found for financial assets. Indeed, in contrast to what is indicated in the theory, the slope of the market line (Security Market Line: SML) is negative for assets whose betas (systematic risks) are negative (Cloninger et al. (2004)). In addition, the results of Cloninger et al. (2004) show that the SML is ' $V$ ' shaped when considering both securities whose betas are positive and securities whose betas are negative. The point of the ' $\mathrm{V}$ ' corresponds to a beta of zero and a return equal to the risk-free rate. Fig 1.1 below shows that the high school and college diplomas are better than a graduate degree because they represent a better risk-return combination (lower risk and higher returns). Although the general belief is that as we advance in studies, the risk decreases and return increases, it should be noted that individuals are faced with a labor market whose needs change over

years.

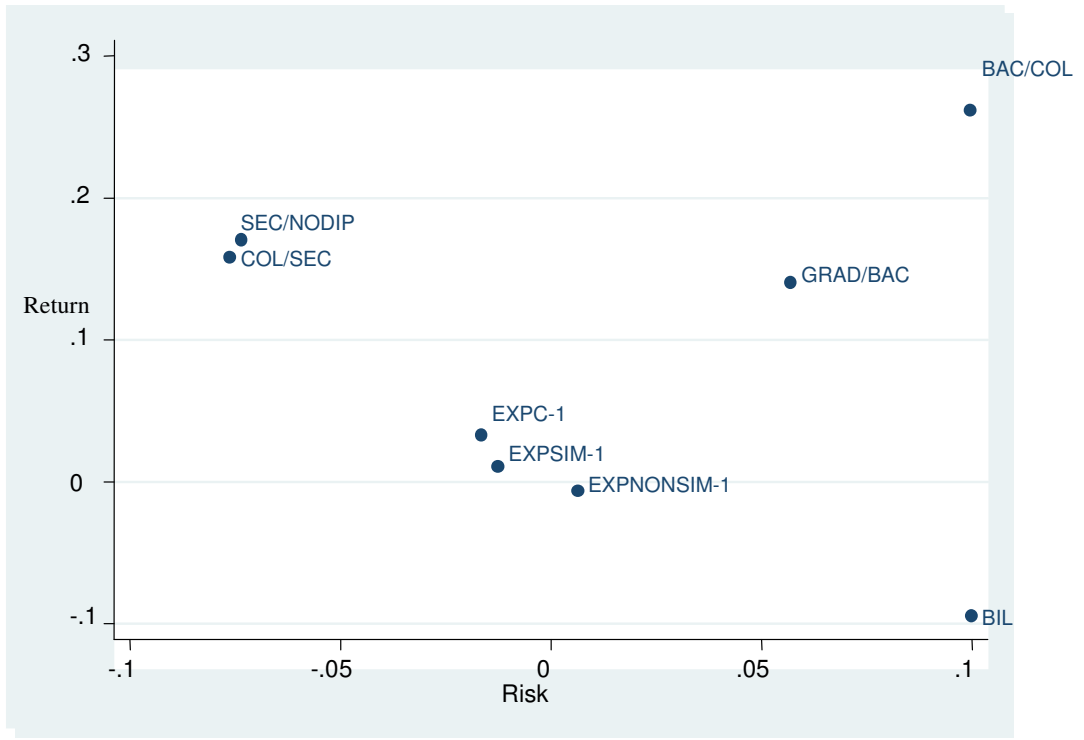

Fig.1: Risk and return on human capital of immigrants

Indeed, a risk of higher education that is relatively high in comparison to that of a college degree may simply reflect both, a strong need, in the labor market, for individuals working in sectors that do not require a high level of education (manufacturing, sales and services ...) and a low demand for individuals who hold a 
university diploma above bachelor level. In this case, people who hold a graduate degree would face a relatively high risk because it is most likely that they cannot find jobs that match their skills and to the level of the investment they have made. This uncertainty faced by individuals concerning their future situation in income distribution is an element of the 'ex ante' risk defined by Hartog et al. (2007). In addition, with regard to secondary and collegial diplomas, the results indicate that these are assets that operate in the opposite direction of the market portfolio. This can be explained as follows: in case of favorable conditions (e.g. technological progress), these assets lose their value. In fact, according to Gould et al. (2001), given that the specific skills are obsolete and that the workers whose level of education is relatively low are generally those who invest in the acquisition of these skills, these diplomas would be depreciated and their owners would have difficulty to get integrated in the new economic environment. However, as in time of recession, job losses would be mainly experienced by newly hired workers (McDonald and Worswick (1997)), it is legitimate to suppose that the impact of the recession on the secondary or college diploma holders would be lesser with respect to university degrees. Indeed, since the decision to pursue studies evokes a choice to forgo acquiring years of professional experience in return for obtaining a higher degree; if we consider two individuals of the same age, one having a high school diploma as the highest degree, the other a bachelor, all other things being equal, the first would have relatively more experience than the last.

\section{Evolution over Time of the Risk And Return Of Labor Market Experience}

The evolution over time of the return and risk of different types of labor market experience is plotted. Fig 1.2 shows that the risk increases and the return decreases gradually as the individual accumulates work experience in Canada or in a similar country. This result may be explained as follows: it is true that the more the individual accumulates experience, the more he would acquire skills; but these are skills that are specific to a certain domain and which might be at risk because they are difficult to transfer. For example, in manufacturing and within a context of globalization, there were many job losses. However, new jobs requiring higher qualifications have been created. The very large experience of employees in manufacture did not help them shifting into other sectors. 


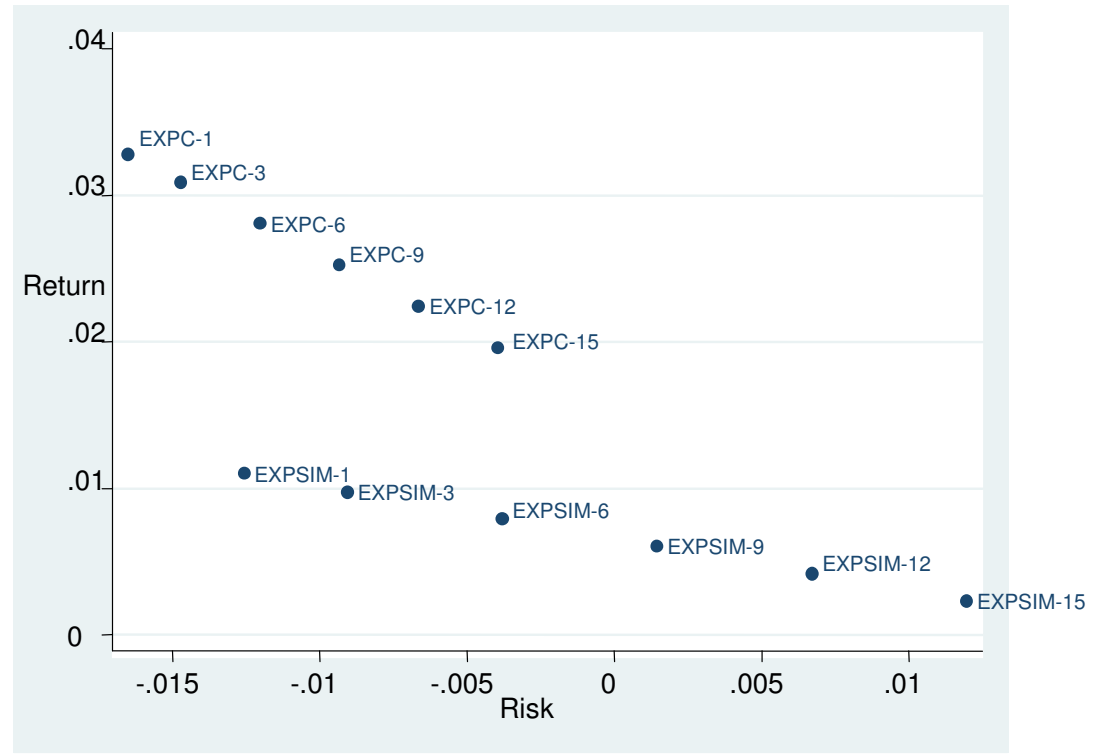

Fig .2: Evolution of the risks and returns on labor market experience in Canada and in a similar country

However, unlike Fig 1.2, Fig 1.3 illustrates that the more the number of years of labor market experience in a country that is not similar to Canada is high, the more the loss due to such investment is low (the return is negative) and the more the risk is higher. This indicates that, all other things being equal, an immigrant who has accumulated many years of experience in his home country will be relatively less disadvantaged in terms of wage. As in the case of financial assets, we observe that a higher risk is associated with a higher return

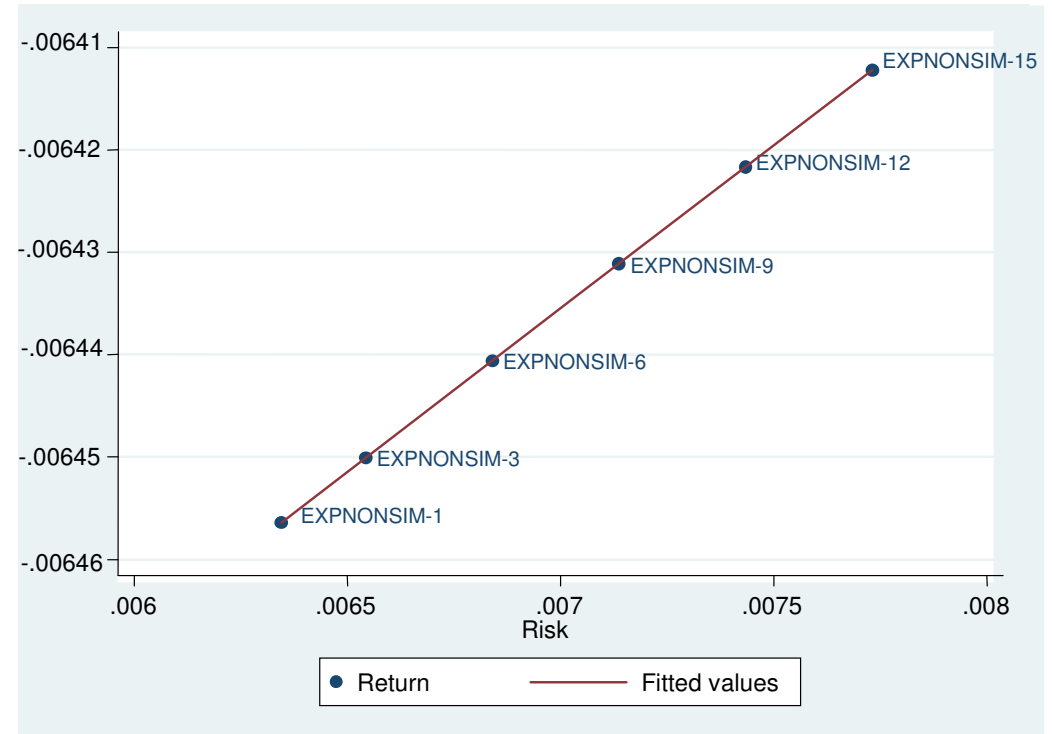

Fig .3: Evolution of the risk and return on labor market experience in a country nonsimilar to Canada 


\section{Conclusion}

In this study, we estimate the returns on some components of the human capital of immigrants. We take account of the impact of the similarity between the country of origin and Canada on wages, through the place of obtaining the highest degree and labor market experience. We also analyze the relationship between risk and return of human capital and compare it to the same relationship in the case of financial assets. In addition, the evolution of the risk and return associated with each type of work experience was examined.

The results indicate a disadvantage in terms of wage for the immigrant who obtained his highest degree in a nonsimilar country, in comparison to the case in which he would have earned it in Canada. In addition, the value of labor market experience of an immigrant depends on the place of its acquisition. It is the work experience in Canada that has the highest return. Labor market experience in a similar country is more valued than that acquired in a non-similar country. The latter has a return that is close to zero. Our results are consistent with those of Friedberg (2000). They show that it is relatively easy for an immigrant originating from a country similar to Canada to transfer his human capital in comparison to an immigrant from a non-similar country.

We find that the relationship between risk and return on human capital is negative for those assets that represent insurance for their owners, while it is positive for the other assets; this is similar to the results of the study of Cloninger et al. (2004) on financial assets.

Moreover, contrary to what one might think, a higher level of education is not necessarily accompanied by a lower risk. Labor market experience in a non-similar country is the one with the highest risk as compared to other types of experience.
Except for the work experience in a nonsimilar country, the more the immigrant accumulates experience, the more the risk would increase and return decrease.

Based on our literature review and to our knowledge, the existence of $\mathrm{a}$ ' $\mathrm{V}$ ' relationship between risk and return associated with the various components of human capital of immigrants was not addressed. It would be interesting to see the impact of another risk measure on the results. In this work, we consider the risk of ending up in the bottom part of the income distribution. We could also evaluate the risk of failing in school, which is another component of the 'ex ante' risk defined by Hartog et al. (2007).

The results suggest that efforts from government, employers and immigrants as well are required to contribute to the success of the integration in Canada: the Canadian government should solve the problem of recognition of qualifications acquired abroad and encourage employers to recruit newcomers by providing, for example, subsidies or tax benefits. The provincial governments should also invest more in professional mentorship programs for newcomers such as 'Québec pluriel' launched by Emploi Québec in 2004. More organisms, with the purpose of accommodating and facilitating the integration of immigrants (such as 'l'Hirondelle' in Quebec), should be implemented. Concerning the regulated occupations or governed by a professional order (doctors, nurses, engineers etc.), as pointed out by Boudarbat and Boulet (2007), it is important to ensure the increase in the capacity of training programs intended to facilitate the integration of immigrants with such qualifications. In addition, the government may eventually impose a minimum number of immigrants in the companies. On their side, the latter should show more openness to immigrants and grant them the necessary time to adapt themselves to the Canadian working mode. The use of internship programs in companies facilitates the integration of 
immigrants. As for the latter, they should arm themselves with patience and courage and consider the possibility to return to school, or to occupy a position which is not necessarily related to their skills in order to improve their chances of finding jobs up to their expectations. As the results indicate that obtaining the highest degree abroad may represent a disadvantage for immigrants, the fact of arriving early in Canada to pursue studies before starting to work would facilitate the integration of the immigrant as it would initiate a period of adaptation to Canadian society. However, the tuition fees for foreign students are relatively very high, which could discourage them. We therefore believe that provincial governments should review their tuition fee waiver program to enable more students to benefit from the scholarship tuition exemption. Thus, we share the opinion of Boudarbat and Boulet (2007) on the importance of the category of foreign students as potential immigrants. In concrete terms, we believe that if more efforts are made to retain the latters, particularly in Quebec, the problem of an aging population (which is the major cause of expected bankruptcy of the 'Quebec Pension Plan' in 2039) would be partly solved.

All these proposals have one point in common: to contribute to the success of the socio-professional integration of immigrants in Canada. Thus, the risks (to find themselves in the bottom part of wage distribution) associated with skills acquired abroad would be substantially reduced if additional efforts are provided to facilitate the recognition of the foreign human capital. To leave one's country and family and restart life from scratch in a foreign country requires a lot of courage. In the current economic and demographic contexts, it is the responsibility of all that the immigrants succeed in their socioeconomic integration because the problems of aging population and shortage of skilled workers, which are at the origin of immigration policy in Canada, would only get worse.

\section{Notes}

1. In his study dealing with the investment in the human capital, Palacios-Huerta (2003a) considers that each asset is a combination of an educational level and labor market experience. His methodology is, however, different from ours.

2. Mincer (1974) expresses the incomes as a function of education and labor market experience. Estimating this equation allows the calculation of the rate of return on education.

3. We have also estimated a model for native Canadians $\quad 63792$ observations) and redone the estimations with the 1996 data $(9053$ observations for immigrants and 59478 for natives). The results are available upon request. Note, however, that all things being equal, the results of 2001 indicate that natives have a higher return on labor market experience in comparison to that of immigrants, thus confirming the idea of an undervaluation of the human capital of immigrants.

4. The wages reported are those relating to the reference year.

5. As one may exceed the number of years required to earn a degree, the highest earned degree is considered as a most appropriate measure.

6. In the category 'College', we include the certificate or diploma of trade schools together with the certificate or university diploma below the bachelor level. 'Graduate' includes all degrees corresponding to levels that are above bachelor degree. 
7. Schaafsma and Sweetman (2001) distinguish between three categories for education: the number of years of study in Canada, the number of years of study abroad, and the 'unknown' number of years of study. This corresponds to the rest of the total number of years of study once we deduct education in Canada and abroad. The same distinction applies to labor market experience. Schaafsma and Sweetman (2001) justify the existence of the third category by the fact that the age at immigration is given as intervals. Unlike them, we do not consider this component, since we estimate the age at immigration as explained in the text.

8. We consider the grid established by the Canadian Information Centre for International Credentials (CICIC) available at the following address: http://www.cicdi.ca/docs/postsec/gr aphics/EducationSystem_Canada.pdf.

9. According to the Council of Ministers of Education, the U.S., the UK, Australia, New Zealand, and most European countries have education systems that are similar to those in Canada.

10. A better way to proceed would be to separate the developed countries of the Organization for Economic Cooperation and Development (OECD) from the undeveloped countries. However, as mentioned above, the grouping of countries in the census does not allow doing so.

11. Although it is preferable to further refine the selection of countries, the fact that they are sometimes presented as a group is an obstacle to a better selection.

12. Although this is the base model, the results reported and their interpretation will focus on variants of this model where some interaction variables have been removed (due to non-significance).

13. Hanchane et al. (2006, p.17) define the opportunity cost as the labor income which the individual gives up by continuing his studies.

14. For education, we determine the risk of an educational level compared to the immediately lower level. For example, for the bachelor, we calculate its risk compared to a certificate or diploma of college studies.

15. Pereira and Martins (2002) use the absolute value of the difference between the coefficients because they find that among the 16 countries considered in their study, there is a country (Greece) for which the coefficient of education in the regression of the1st decile exceeds that on the 9th decile.

16. This goes beyond the scope of this study and might be considered in future work.

17. Although SIM and NONSIM variables were included in the model, the risk associated with studies abroad will not be analyzed herein.

18. For education, we represent the risk and return of each study level compared to the level immediately below. Regarding labor market experience, the return and risk being represented are relative to the first year. However, we will also report the changes over time in the risk and return of different labor market experiences. NODIP is a dummy variable that takes the value 1 when the individual has no diploma.

19. Similarly, the investment in vocational training on the part of the 
employee has the same effect (Borjas (2005)).

20. According to McDonald and Worswick (1997), in a period of recession, the new workers are the most vulnerable to dismissal. Moreover, according to Kogan (2004), the fact of having accumulated many years of experience within a company protects employees against dismissal, given the human capital specific to this company that he accumulated thanks to this experience.

21. This result does not apply to the secondary diploma and the bilingualism assets. The secondary diploma is both a more risky and more profitable asset than college diploma.

22. We have also considered the absolute value of risk measurement. In this case, the risk and return are positively linked.

23. The market line displays the expected return of a security as a fuction of its beta.

24. In particular, we reported the results for the 1st, 3rd, 6th, 9th, 12th, and 15 th years of experience

\section{References}

1.Andini, C. (2009), 'On the Return-risk Link in Education', Applied Economics Letters, 16, 307-14.

2.Aydemir, A. and Skuterud, M. (2005), 'Explaininig the Deteriorating Entry Earnings of Canada's Immigrant Cohorts, 1966-2000', Canadian Journal of Economics, 38, 641-72.
3. Boudarbat, B. and Boulet, M. (2007), 'Détérioration des Salaires des Nouveaux Immigrants au Québec par rapport à l'Ontario et à la Colombie-Britannique', IRPP Choix, 13, Institut de Recherche en Politiques Publiques, Montréal, 1-30.

4. Campbell, J.Y. (1996), 'Understanding Risk and Return', The Journal of Political Economy, 104, 298-345.

5. Campbell, SD. and Korniotis GM. (2008), "The Human Capital that Matters: Expected Returns and the Income of Affluent Households', Finance and Economics Discussion Series 2008-2009, Federal Reserve Board, Washington, D.C.

6. Christiansen, C., Joensen JS. and Nielsen HS. (2007), 'The Risk-Return Trade-off in Human Capital Investment', Labour Economics, 14, 971-86.

7. Christiansen C., Joensen JS. and Rangvid J. (2008), 'Are Economists More Likely to Hold Stocks? Review of Finance, 12, 46596.

8. Cloninger, DO., Waller, ER., Bendeck Y. and Revere L. (2004), 'Returns on Negative Beta Securities: Implications for the Empirical SML', Applied Financial Economics, 14, 397-402.

9. Finnie, R. and Meng, R. (2002), 'Are Immigrants' Human Capital Skills Discounted in Canada', Canadian Employment Research Forum, Conference on Immigration, University of Calgary, Calgary, Alberta (May).

10. Friedberg, RM. (2000), 'You Can't Take it With you? Immigrant Assimilation and the Portability of Human Capital', Journal of Labor Economics, 18, 221-51.

11. Gould, ED., Moav O. and. Weinberg BA (2001), 'Precautionary Demand for Education, Inequality, and Technological Progress', Journal of Economic Growth, 6, 285-315. 
12. Hanchane, S., Lioui A. and Touahri D. (2006), 'Human Capital as a Risky Asset and the Effect of Uncertainty on the Decision to Invest', Pre- and Post-Print documents halshs-00010139_v1, HAL, CCSD, CNRS.

13. Hartog, J., Van Ophem H. and Bajdechi S. M. (2007), 'Simulating the Risk of Investment in Human capital', Education Economics, 15, 259-75.

14. Hartog, J. and Vijverberg W. (2007), 'Schools, Skills and Risk', Economics of Education Review, 26, 759-71.

15. Jagannathan, R., Kubota K. and Takehara H. (1998), 'Relationship Between Labor-Income Risk and Average Return: Empirical Evidence from the Japanese Stock Market', Journal of Business, 71, 319-48.

16. Jagannathan, R. and Wang Z. (1993), 'The CAPM is Alive and Well', Research Department Staff Report 165, Federal Reserve Bank of Minneapolis.

17. Jagannathan, R. and Wang Z. (1996), 'The Conditional CAPM and the CrossSection of Expected Returns', Journal of Finance, 51, 3-53.

18. Kogan, I. (2004), 'Last Hired, First Fired? The Unemployment Dynamics of Male Immigrants in Germany', European Sociological Review, 20, 445-61.

19. Levhari, D. and Weiss Y. (1974), 'The Effect of Risk on the Investment in Human
Capital', The American Economic Review, 64, 950-63.

20. Machado, JAF. and Mata J. (2001), 'Earnings Functions in Portugal 19821994: Evidence from Quantile Regressions', Empirical Economics, 26, 115-34.

21. McDonald, JT. and Worswick C. (1997), 'Unemployment Incidence of Immigrant Men in Canada', Canadian Public Policy, 23, 353-73.

22. Mincer, J. (1974), 'Schooling, Experience and Earnings', NBER, New York.

23. Palacios-Huerta, I. (2003a), 'An Empirical Analysis of the Risk Properties of Human Capital Returns', The American Economic Review, 93, 948-64.

24. Palacios-Huerta, I. (2003b), 'The Robustness of the Conditional CAPM with Human Capital', Journal of Financial Econometrics, 1, 272-89.

25. Pereira PT. and Martins PS. (2002), 'Is there a Return-Risk link in Education?, Economics Letters 75, 31-7.

26. Schaafsma, J. and Sweetman A. (2001), 'Immigrant Earnings: Age at Immigration Matters', Canadian Journal of Economics, 34, 1066-99.

27. Statistics Canada (2010), 'Projections of the Diversity of the Canadian Population 2006-2031', Catalogue no. 91551-X, Ottawa. 